\title{
Titanium Tetrafluoride/L-Prolinol Catalyzed Enantioselective Allylation of Aromatic Aldehydes with Allyltrimethylsilane
}

\author{
SAROJ K NAYAK, SUBHENDU DAS and RAJESH K SINGH* \\ Department of Chemistry, North Orissa University, Takatpur, \\ Baripada-757003, Orissa, India \\ rajeshks2001@yahoo.com
}

Received 21 April 2014 / Accepted 16 May 2014

\begin{abstract}
Aldehydes undergo smooth conversion to give homoallylic alcohols with allyltrimethylsilane employing $10 \mathrm{~mol} \%$ of titanium tetrafluoride as a Lewis acid in the presence of $10 \mathrm{~mol} \%$ of $\mathrm{L}$-prolinol in $\mathrm{CH}_{3} \mathrm{CN} / \mathrm{CH}_{2} \mathrm{Cl}_{2}$ (8:2) for $2 \mathrm{~h}$ at room temperature. The presence of functionalities such as chloro, nitro and bromo is well tolerated in the presence of catalyst. The reaction proved to be of general nature with yields varying from moderate to excellent depending on the structure of aldehydes used to give enantiomerically enriched homoallylic alcohols. The reaction proceeds under mild condition with simple experimental procedures.
\end{abstract}

Keywords: Aldehydes, Allylation, Titanium tetrafluoride, $L$-Prolinol, Allyltrimethylsilane

\section{Introduction}

The allylation of carbonyl compounds is among the most important methods for the formation of homoallylic alcohol ${ }^{1}$. Homoallylic alcohols so obtained are important building blocks for the synthesis of various natural products ${ }^{2}$. Many of these transformations typically employ Lewis acid and have attracted tremendous interest throughout scientific communities witnessing unprecedented advances in the last decade. A large arsenal of Lewis acids catalyst thus have been documented so far $^{1 \mathrm{a}, 3}$ leading to development of a large and diverse array of chiral Lewis acid catalysts. Most of them consist of chiral ligands attached to metals such as $\mathrm{Zn}, \mathrm{Ti}, \mathrm{B}, \mathrm{Cr}$ and Rh. Among the chiral modifiers to accomplish this are ligands such as bisoxazolines, bipyridines and terpyridine. Among the allyl transfer reagents allylic silanes and allylic stannanes have been extensively employed. A limitations to some of these protocols is the toxicity, moisture uptake, air tolerance and few of them employing expensive rare earths as Lewis acid catalyzed addition of the allyl transfer reagents to carbonyl functionality. Thus the development of new synthetic methods of a benign nature is of great interest today.

Of particular interest in this context is the use of metal fluorides like $\mathrm{TiF}_{4}, \mathrm{CsF}$ and $\mathrm{AgF}$ as activators that promotes allylation of aldehydes and has long been of interest to synthetic chemist $^{4}$. A common strategy is to use titanium diol coordination chemistry by employing 
titanium tetrafluoride with complexes of the readily available bidentate chiral ligands such as 1,1'-binaphthalene-2,2'-diol (BINOL) complexes as the catalysts. The high reactivity of the catalyst is attributed to factors such as the strong Lewis acidity of $\mathrm{TiF}_{4}$ derived complexes and the greater strength of the Ti-F bond compared to the Si-F bond which assists in catalyst turnover. In addition, a ternary transition structure has been proposed in which the electrophilic titanium center activates the aldehyde and the nucleophilic fluoride bridge to silicon increases the reactivity of allylsilane. Fluoride assisted conversions often proceeds with high degree of stereoselectivity ${ }^{5}$. Prolinol is used in broad variety of chemical reactions as chiral ligand, chiral catalyst or chiral auxiliary reagent in the Hajos-Parrish-Eder-Sauer-Wiechert reaction, the BaylisHillman reaction, Noyori type reaction and the Michael reaction ${ }^{6}$. Recently a combination of small dual molecules $L$-proline and $L$-prolinol has been reported to catalyze allylation of aldehydes by (triallyl)butylstannane ${ }^{7}$. With these precedence we herein report the nucleophilic addition of allyltrimethylsilane with titanium tetrafluoride in the presence of $L$-prolinol as chiral bidentate modifiers. It is noteworthy that $L$-proline and $L$-prolinol has have been shown to act as enantioselective catalysts for aldol reactions. In the present protocol reaction was performed between aldehyde substrate and allyltrimethylsilane using an optimum combination of titanium tetrafluoride and $L$-prolinol in $\mathrm{CH}_{3} \mathrm{CN} / \mathrm{CH}_{2} \mathrm{Cl}_{2}$. The reaction proved to be of general nature, yields varying from moderate to excellent, proceeds under mild condition with reasonably low catalyst loading at room temperature to give enantiomerically enriched homoallylic alcohols. The reaction is easy to perform with simple experimental and isolation procedures.

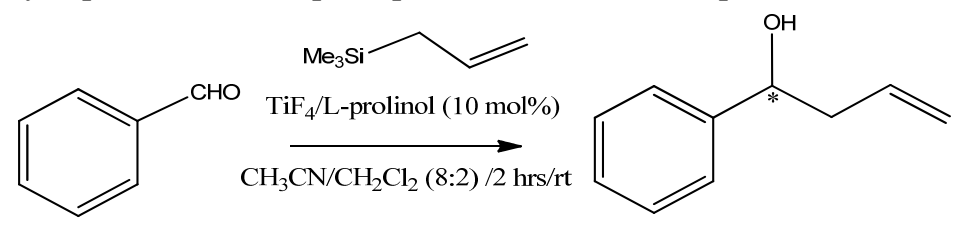

Scheme 1. $\mathrm{TiF}_{4}$ fluoride catalyzed allylation of benzaldehyde using allyltrimethylsilane in the presence of $L$-prolinol

\section{Experimental}

General reagents and solvents were purchased from commercial sources and used without further purification. Starting materials (glycerophosphocholine and acid chloride) reagents were purchased from Aldrich and used as received. Titanium tetraisopropoxide and triethyl amine were obtained from Merk India limited. NMR spectra were obtained using a Varian Mercury 400 instrument spectrometer. EI mass spectra were obtained in FAB+ ion mode with Bruker mass spectrometer. Reactions were carried out using syringe-septum technique. Column chromatography was performed using silica gel 100-200 mesh. Thin layer chromatography was done using manually coated plates, with visualization of spots in iodine chamber.

\section{General procedure for the allylation of $\mathbf{1 a}$}

A mixture of $\mathrm{TiF}_{4}(0.1 \mathrm{mmol})$ and ligand $(0.1 \mathrm{mmol})$ in $\mathrm{CH}_{3} \mathrm{CN} / \mathrm{CH}_{2} \mathrm{Cl}_{2}(8: 2)$ was stirred for 15 minutes at room temperature. Aldehyde $1 \mathrm{a}(1 \mathrm{mmol})$ and allyltrimethylsilane 2 (3 mmol) was then sequentially added at room temperature. The reaction mixture was allowed to stir for appropriate time. After the completion of the reaction (TLC monitored), solvent removed in vaccuo, the reaction mixture was quenched with $2 \mathrm{~N} \mathrm{HCl}(10 \mathrm{~mL})$ and extracted with diethylether several times. The combined organics was washed with water, sat. brine, dried over anhydrous $\mathrm{Na}_{2} \mathrm{SO}_{4}$, filtered and concentrated. Further purification of the desired product was done on silica gel column. Characterization of alcohol products via NMR and MS was done 
with reference to literature values: 1-Phenyl-3-en-1-ol (3a) $)^{8 a}$, 1-(4-bromophenyl)but-en-1-ol $(\mathbf{3 b})^{8 \mathrm{~b}}$, 1-(4-nitrophenyl) but-3-en-1-ol (3c) ${ }^{8 \mathrm{a}}, 1$-(4-methoxyphenyl)-3-buten-1-ol (3d) ${ }^{8 \mathrm{c}}, 1$ Pyridin-3-yl)but-3-en-1-ol (3e) ${ }^{8 \mathrm{~d}}$, 1-(Furan-2-yl)but-3-en-1-ol (3f) ${ }^{8 \mathrm{e}}$, 1-(4-Dimethylaminophenyl)-but-3-en-1-ol (3g) ${ }^{8 f}$, Dec-1-en-4-ol (3h) $)^{8 g}$.

\section{Results and Discussion}

Benzaldehyde (1a) was examined as a model substrate and the reaction conditions was optimized by screening the solvents such as $\mathrm{CH}_{3} \mathrm{CN}, \mathrm{CH}_{2} \mathrm{Cl}_{2}, \mathrm{Et}_{2} \mathrm{O}$, dioxane and THF, changing the ratio of benzaldehyde (1a)/allyltrimethylsilane (2) and by varying of the catalyst loading (Table 1$)$. Under the optimized condition the best results (82\% yield) were obtained by stirring the reaction mixture using a substrate ratio of $1: 3(\mathbf{1 a} / \mathbf{2})$ and $10 \mathrm{~mol} \%$ of titanium tetrafluoride in the presence of $10 \mathrm{~mol} \%$ of $L$-prolinol in $\mathrm{CH}_{3} \mathrm{CN} / \mathrm{CH}_{2} \mathrm{Cl}_{2}$ (8:2) for $2 \mathrm{~h}$ at room temperature. Among the halogenated solvents $\mathrm{CH}_{2} \mathrm{Cl}_{2}$ gave the best observed yields and selectivity. The use of ethereal solvents such as THF, dioxane and ether proved beneficial in terms of selectivity but gave lower yields (Table 1. Entry 1, 2 and 4). However the use of protic solvent like $\mathrm{MeOH}$ considerably reduced the yield and also selectivity. Consistent with the previous studies the presence of acetonitrile as solvent was necessary for the reaction to proceed to a optimum extent (1e) and a study of variation in the catalyst composition revealed a ratio of $1: 1$ (metal/ligand) to be optimum. Increasing the amount of catalyst to $20 \%$ of $\mathrm{TiF}_{4}$ and $20 \mathrm{~mol} \%$ of ligand showed a decrease in the product yield from $82 \%$ to $68 \%$ (entry 6). However reducing the catalyst loading to less than $5 \mathrm{~mol} \%$ of $\left(\mathrm{TiF}_{4}\right)$ and $5 \mathrm{~mol} \%$ of ligand, the yield of 3a was significantly reduced to $45 \%$ (entry 8). With the use of 10 mol\% of catalyst longer reaction times increased the yields but furnished lower selectivity. The catalytic action of $\mathrm{TiF}_{4}$ was evident as no reaction product was observed under the optimized condition when a solution of 1 a in $\mathrm{CH}_{3} \mathrm{CN} / \mathrm{CH}_{2} \mathrm{Cl}_{2}$ (8:2) was charged directly with allyltrimethylsilane $\mathbf{2}$ in the presence of the catalyst even after prolonged time.

Table 1. Effect of reaction condition on the $\mathrm{TiF}_{4}$ catalyzed allylation of aldehyde (1a) using allyltrimethylsilane (2) in the presence of $L$-prolinol

\begin{tabular}{clcccc}
\hline Entry & Solvent ratio (8:2) & Time, $\mathrm{h}$ & Catalyst, mol\% & Yield, \% & er $^{*}$ \\
\hline 1 & $\mathrm{CH}_{3} \mathrm{CN} / \mathrm{Et} \mathrm{O}_{2} \mathrm{O}$ & 2 & 10 & 56 & $91 / 9$ \\
2 & $\mathrm{CH}_{3} \mathrm{CN} / \mathrm{THF}$ & 2 & 10 & 30 & $83 / 17$ \\
3 & $\mathrm{CH}_{3} \mathrm{CN} / \mathrm{MeOH}$ & 2 & 10 & 25 & $65 / 35$ \\
4 & $\mathrm{CH}_{3} \mathrm{CN} / \mathrm{Dioxane}$ & 2 & 10 & 45 & $74 / 26$ \\
5 & $\mathrm{CH}_{3} \mathrm{CN} / \mathrm{CHCl}_{3}$ & 2 & 10 & 72 & $75 / 25$ \\
6 & $\mathrm{CH}_{3} \mathrm{CN} / \mathrm{CH}_{2} \mathrm{Cl}_{2}$ & 2 & 10 & 82 & $80 / 20$ \\
7 & $\mathrm{CH}_{3} \mathrm{CN} / \mathrm{CH}_{2} \mathrm{Cl}_{2}$ & 2 & 20 & 68 & $86 / 14$ \\
8 & $\mathrm{CH}_{3} \mathrm{CN} / \mathrm{CH}_{2} \mathrm{Cl}_{2}$ & 2 & 5 & 45 & $70 / 30$ \\
9 & $\mathrm{CH}_{3} \mathrm{CN} / \mathrm{CH}_{2} \mathrm{Cl}_{2}$ & 5 & 10 & 82 & $65 / 35$ \\
\hline
\end{tabular}

${ }^{*}$ The enantiomeric ratio was determined by HPLC analysis employing a Daicel Chiracel OD column (Hexane: i-propanol)

With the optimized condition in hand we then evaluated the scope of the reaction using a variety of structurally divergent aldehydes (Table 2). While with benzaldehyde $82 \%$ of allylated product was obtained under the optimized condition in $2 \mathrm{~h}$, activated 3-nitrobenzaldehyde afforded the allylated product in 92\% yield in the same $2 \mathrm{~h}$ conversion. 
An electron withdrawing substituent on the ring facilitated a nucleophilic attack on the carbonyl while with the presence of an electron donating substituent (deactivated aryl aldehydes), the reaction was sluggish and a longer reaction time was registered for an acceptable yield. As anticipated the allylation of electron rich heteroaromatics (1e and 1f) also took a longer reaction time to accomplish. These observed rates can be explained on the basis of simple arguments based on electronic effects of groups present on the ring. As shown in Table 2, all the aldehydes including enolizable aldehydes furnished the products in high enantioselectivities (74-84\%) in good yields.

Table 2. Fluoride catalyzed allylation of aldehyde 1a using allyltrimethylsilane in the presence of $L$-prolinol

(1)

${ }^{a}$ Isolated yields. ${ }^{b}$ All compounds gave satisfactory microanalyses and were characterized by ${ }^{1} \mathrm{H}$ NMR spectra by direct comparision with reported authentic samples ${ }^{8}$. Typical reaction condition: aldehyde:allyltrimethylsilane (1:3), $10 \mathrm{~mol} \%$ catalyst combination: $\mathrm{TiF}_{4}$ in $\mathrm{CH}_{3} \mathrm{CN}: \mathrm{CH}_{2} \mathrm{Cl}_{2}$ (8:2). The enantiomeric excess was determined by HPLC analysis employing a Daicel Chiracel OD column (Hexane: i-propanol) 
The reaction proved to be of general nature and could be applied to a broad range of substrates. Both aromatic and aliphatic aldehydes gave good yields. The reaction proceeds under mild condition and even aliphatic enolizable aldehydes can be allylated (Table 2, entry 8). Under the optimized condition ketones were not allylated. A study of variation in the catalyst composition revealed that employing a $0.5 \mathrm{~mol} \% \mathrm{TiF}_{4}$ with respect to the ligand ( $5 \mathrm{~mol} \%$ of $\mathrm{TiF}_{4}$ and $10 \mathrm{~mol} \%$ of ligand) still enabled a satisfactory yield within a period of $3 \mathrm{~h}$. Even with only $2.5 \mathrm{~mol} \%$ of $\mathrm{TiF}_{4}$ with respect to ligand, $75 \%$ of the allylated product was obtained in a $6 \mathrm{~h}$ conversion. These observations suggests that the relationship between $\mathrm{TiF}_{4}$ and ligand is not a simple stoichiometric one. As can be judged from Table 1. the use of ethereal solvents provided greater variation in the product yields (Table 2, entry 1 and 2). Presumably, the coordination of solvent in the transition state influences the product formation in these transformations. By conducting the reaction over a range of decreasing catalyst loading (starting from 20 mol\% of catalyst) and keeping the concentration of the substrate constant we found an inverse relationship between the catalyst loading and the chemical yield. Decreasing the amount of catalyst led to a steady increase of the product till an optimum value at $10 \mathrm{~mol} \%$ of loadings. Since a catalytic amount of $\mathrm{TiF}_{4}$ is required to accomplish the reaction following transition state may be proposed ${ }^{9}$ involving initial activation of allyltrimethylsilane to to the increased electrophilicity of carbonyl carbon coordinated to titanium (Scheme 2).

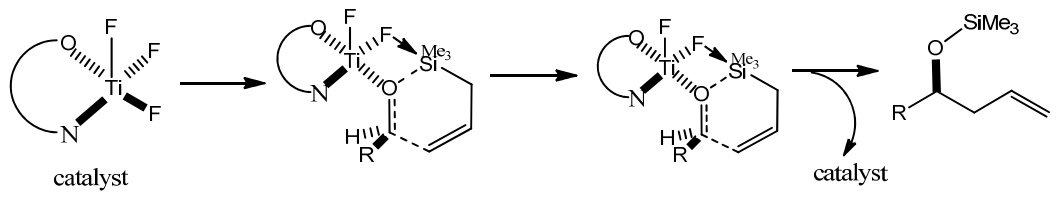

Scheme 2. Plausible mechanism for the $\mathrm{TiF}_{4}$ fluoride catalyzed allylation of aldehyde using allyltrimethylsilane in the presence of $L$-prolinol

\section{Conclusion}

In conclusion a convenient and practical method for the synthesis of enantiomerically rich homoallylic alcohol in good yields in the presence of catalytic amount of $L$-prolinol and $\mathrm{TiF}_{4}$ and in a one-pot reaction procedure has been accomplished under a mild reaction condition. We have demonstrated the scope and a novel use of $L$-prolinol as a ligand in the catalytic allylation reactions. The reaction smoothly proceeds without pretreatment of the reagents and uses no additives. The mild reaction condition and low cost of reagent should make the present methodology synthetically useful.

\section{Acknowledgement}

The authors gratefully acknowledge the financial support from the Council of Scientific and Industrial Research (CSIR) and University Grants Commission (UGC) New Delhi.

\section{References}

1. (a) Yamamoto Y and Asao N, Chem Rev., 1993, 93(6), 2207-2293; DOI:10.1021/cr00022a010 (b) Helmchen G, Hoffmann R, Mulzer J and Schaumann E, Stereoselective Synthesis Methods in Organic Chemistry, 1996, 3, $135721^{\text {st }}$ Ed., (Houben-Weyl), Thieme, Stuttgart; (c) Chemler S R, Roush W R, Methods in Carbonyl Chemistry (Ed., Otera J), Chap 11, Wiley-VCH, Weinheim, 2000; (d) Denmark S E, Almstead N G, Modern Carbonyl Chemistry (Ed., Otera J), Chap 10, Wiley-VCH, Weinheim, 2000; (e) Denmark S E and Jiping Fu, Chem Rev., 2003, 103(8), 2763-2794; DOI:10.1021/cr020050h. 
2. (a) Hoenberer K R, Hamblet C L and Leighton J L, J Am Chem Soc., 2000, 122(48), 12894-12895; DOI:10.1021/ja003593m (b) Reddy M V R, Rearick J P, Hoch N and Ramachandran P V, Org Lett., 2001, 3(1), 19-20; DOI:10.1021/ol006583z (c) Roush W R, Comprehensive Organic Synthesis; Trost B M, Fleming I and Heathcock C H, Eds., Vol. 2, p-1. Pergamom: Oxford, 1991; (d) Nicolou K C, Khim D W and Baati R, Angew Chem Int Ed., 2002, 41(19), 3701-3704;

DOI:10.1002/1521-3773(20021004)41:19<3701::AID-ANIE3701>3.0.CO;2-4

3. (a) Araki S, Jin S J, Idou Y and Butsugam Y, Bull Chem Soc Jpn., 1992, 65(6), 17361738; DOI:10.1246/bcsj.65.1736 (b) Yasuda M, Onishi Y, Ito T and Baba A, Tetrahedron Lett., 2000, 41(14), 2425-2428; DOI:10.1016/S0040-4039(00)00178-7 (c) Marshall J A and Hinkle K W, J Org Chem., 1996, 61(1), 105-108; DOI:10.1021/jo951563+ (d) Andrade C K Z, Azevedo N R and Oliveira G R, Synthesis, 2002, 7, 928-936; (e) Kobayashi S, Synlett., 1994, 689-701; (f) Marshman R W, Aldrichim Acta, 1995, 28, 77; (g) Hachiya I and Kobayashi S, J Org Chem., 1993, 58(25), 6958-6960; DOI:10.1021/jo00077a009

4. Sato K, Kira M and Sakuri H, J Am Chem Soc., 1989, 111(16), 6429-6431; DOI:10.1021/ja00198a069 (b) Cerveau G, Chuit C, Corriu R J P and Reye C, J Organomet Chem., 1987, 328(3), C17-C20; DOI:10.1016/0022-328X(87)80257-7 (c) Hosomi A, Kohara S and Tominaga Y, J Chem Soc Chem Commun., 1987, 15171518; DOI:10.1039/C39870001517 (d) Bode J W, Gauthier D R Jr and Carreira E M, Chem Commun., 2001, 2560-2561; DOI:10.1039/B107995F (e) Duthaler R O and Hafner A, Angew Chem Int Ed Engl., 1997, 36(1-2), 43-45; DOI:10.1002/anie.199700431 (f) Gauthier D R Jr and Carreira E M, Angew Chem Int Ed Engl., 1996, 35(20), 23632365; DOI:10.1002/anie.199623631 (g) Yanagisawa A, Kageyama H, Nakatsuka Y, Asakawa K, Matsumoto Y and Yamamoto H, Angew Chem Int Ed Engl., 1999, 38(24), 3701-3703;

DOI:10.1002/(SICI)1521-3773(19991216)38:24<3701::AID-ANIE3701>3.0.CO;2-D

(h) Sakurai H, In Proceedings of the $5^{\text {th }}$ International Kyoto Conference on New Aspects of Organic Chemistry; Yoshida Z I and Ohshiro Y, Eds., Kodansha Press, Tokyo, Japan, 1992, 129-157; (i) Kobayashi S and Nishio K, J Org Chem., 1994, 59, 6620-6628; DOI:10.1021/jo00101a021

5. (a) Yanagisawa A, Kageyama H, Nakatsuka Y, Asakaw K, Matsumoto Y and Yamamoto H, Angew Chem., 1999, 111(24), 3916-3919; DOI:10.1002/(SICI)15213757(19991216)111:24<3916::AID-ANGE3916>3.0.CO;2-V (b) Wada R, Oisaki K, Kanai M and Shibasaki M, J Am Chem Soc., 2004, 126(29), 8910-8911; DOI:10.1021/ja047200l (c) Wadamoto M and Yamamoto H, J Am Chem Soc., 2005, 127, 14556-14557; DOI:10.1021/ja0553351 (d) Gastner T, Ishiba H, Akiyama R and Kobayashi S, Angew Chem., 2001, 113(10), 1949-1951;

DOI:10.1002/1521-3757(20010518)113:10<1949::AID-ANGE1949>3.0.CO;2-K

(e) Farnandes R A and Yamamoto Y, J Org Chem., 2004, 69(3), 735-738; DOI:10.1021/jo035453b (f) Itoh T, Miyazaki M, Fukuoka H, Nagata K and Ohsawa A, Org Lett., 2006, 8(7), 1295-1297; DOI:10.1021/ol0530326 (g) Wadamoto M, Ozasa N, Yanagisawa A and Yamamoto H, J Org Chem., 2003, 68(14), 5593-5601; DOI:10.1021/jo020691c (h) Aoyama N, Hamada T, Manabe K and Kobayashi S, J Org Chem., 2003, 68(19), 7329-7333; DOI:10.1021/jo0346196 (i) Aoyama N, Hamada T, Manabe K and Kobayashi S, Chem Commum., 2003, 676; (j) Kobayashi S, Aoyama N and Manabe K, Synlett., 2002, 483.

6. (a) Benjamin List, Tetrahedron, 2002, 50(20), 5573-5590; DOI:10.1016/S00404020(02)00516-1 (b) Shinichi Itsuno, Koichi Ito, Akira Hirao and Seiichi Nakahama, J Chem Soc., Perkin Trans., 1984, 1(12), 2887-2895; DOI:10.1039/P19840002887 
7. Guo Hong Chen, Ling Yan Liu, Wei Xiao Ning, Chang Wei-xing and Li Jing, Chem Lett., 2010, 39(9), 1013-1015.

8. Furstner A and Voigtlander D, Synthesis, 2000, 959-969; (b) Yanagisawa A, Nakamura Y and Arari T, Tetrahedron: Asymmetry, 2004, 15(12), 1909-1913; DOI:10.1016/j.tetasy.2004.04.036 (c) Shibato A, Itagaki Y, Tayama E, Hokke Y, Asao N and Maruoka K, Tetrahedron, 2000, 56(30), 5373-5382; DOI:10.1016/S0040-4020(00)00458-0 (d) Felpin F X, Bertrand M J and Lebreton J, Tetrahedron, 200), 58(37), 7381-7389; DOI:10.1016/S0040-4020(02)00819-0 (e) Singh S, Kumar S and Chimmi S S, Tetrahedron: Asymmetry, 2002, 13(24), 26792687; DOI:10.1016/S0957-4166(02)00743-7 (f) Wang Z, Kisanga P and Verkade J G, $J$ Org Chem., 1999, 64(17), 6459-6461; DOI:10.1021/jo990225w (g) Katzenellenbogen J A and Lennox R S, J Org Chem., 1973, 38(2), 326-335; DOI:10.1021/jo00942a027

9. Duthaler R O and Hafner A, Angew Chem., Int Ed Engl., 1997, 36(1-2), 43-45; DOI:10.1002/anie.199700431 